\title{
Pediatric neurosurgery—science, art, and humility: reflection of personal experience
}

\author{
Tadanori Tomita
}

Received: 6 May 2013 / Accepted: 8 May 2013

(C) The Author(s) 2013. This article is published with open access at Springerlink.com

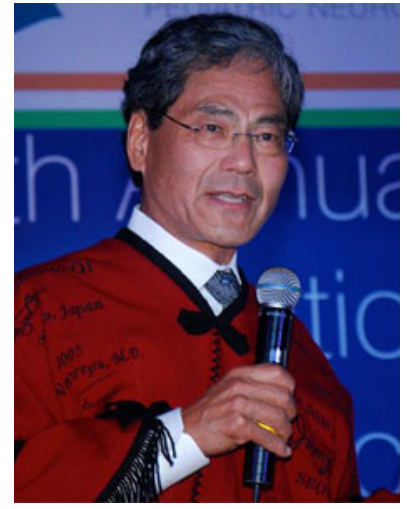

\section{Introduction}

Professor Shizuo Oi, thank you for introducing me and your kind words. You have been my life-long friend and good to me, both personally and professionally. Thank you, Charlie and Genevieve Teo, for hosting this wonderful society meeting in this beautiful city of Sydney, and John Kestle, for a terrific scientific program.

Ladies and gentleman, it is a great honor for me to present my presidential address here in this great city of Sydney in front of my distinguished members and guests. This year makes my 40th year in the profession of neurosurgery since I started my career as a neurosurgery resident in 1972 at Kobe University under Professor Satoshi Matsumoto. It coincides with this year's 40th annual meeting of International Society for Pediatric Neurosurgery (ISPN). I was there in 1973 when the first ISPN annual meeting was held in Keidanren Kaikan

\section{T. Tomita $(\square)$}

Division of Pediatric Neurosurgery, Ann \& Robert H. Lurie

Children's Hospital of Chicago, 225 E. Chicago Avenue,

Chicago, IL 60611-2605, USA

e-mail: ttomita@luriechildrens.org
Hall, Tokyo, Japan. Shizuo and I were assigned to the slide projection team during the meeting, literally pushing the slide cassettes upon the speaker's request of "next slide please."

Because the theme of this year's annual meeting is "Complications," I thought it is a good opportunity to review my published work, particularly those for pediatric posterior fossa tumors, and share my experience with you to analyze if what I did and observed were "right" or "wrong." Often, retrospective views provide a better perspective and guidance to where we should navigate this most complex profession into the future.

I have been fortunate to have mentors, Professors Matsumoto and Anthony Raimondi in my professional life. When I was still a naïve neurosurgery resident, they guided me toward this highly academic field of pediatric neurosurgery. Exposure to my mentors' activities and their philosophy, I set my academic goals on three pillars: clinical service, education, and research. My entire professional life where I worked on these pillars was spent at Children's Memorial Hospital which changed its name to Ann \& Robert H. Lurie Children's Hospital of Chicago after moving to a new beautiful facility in downtown Chicago in June 2012. I have had terrific associates, presently David, McLone, Arthur DiPatri, Robin Bowman, and Tord Alden, over the past decade, running one of the busiest pediatric neurosurgery services in North America. In Children's Memorial Hospital in Chicago, the former chairmen, Luis Amador, Anthony Raimondi, and David McLone, trained numerous pediatric neurosurgeons who have been leaders in various parts of world. Keeping with this tradition, I have trained many American and international fellows and residents. Also, I am privileged to participate in multiple international educational courses for pediatric neurosurgery sponsored by the ISPN Education Committee. I have also emphasized the importance of basic research in pediatric neurosurgery and pediatric brain tumors. At Children's Memorial Research Center (now Lurie Children's Research Center), I am very fortunate to have a Pediatric Neurosurgery 
Research Laboratory with Chandra Shekhar Mayanil, Ph.D. as a leader over 12 years. Shekhar has done relentless efforts to advance neurobiology research, neural tube defect in particular. In the same lab, we have conducted neurosurgical oncology research with Guifa Xi, M.D., Ph.D., and Simone Sredni, M.D., Ph.D. Falk Brain Tumor Research Program over the past 16 years of which I have been a director has focused on genetic and epigenetic research presently under the leadership of Bento Soares, Ph.D.

During my medical school years from 1966 to 1970, at Kobe University, Kobe, Japan, neuroscience attracted me; partly because I was fascinated by Frank Netter's neuroanatomy book during my freshman year and of course because of Ben Casey on the TV show in the mid-1960s. After graduating Kobe in 1970, I was accepted to be a rotating intern with special emphasis on neurological surgery at St. Luke's International Hospital in Tokyo. It was that year of internship that drew my interest to the care of children, particularly kids with cancer. Two episodes that I encountered drove me to the field of pediatric neurosurgery and brain tumor. One was a 10-year-old blind boy, Koh-chan, who had a large recurrent cystic craniopharyngioma and was treated at St. Luke's by frequent Ommaya taps to drain the cyst. His symptoms rapidly improved after each tap. But that was the only thing that we could do, so I was told by my chief. Unfortunately, I do not know what happened with Koh-chan after I left St. Luke's. Another one is a story written by a Japanese novelist, Junichi Watanabe, about a young neurosurgeon's devotion to a boy with pontine glioma. It was televised in the evening, a sort of soap opera, and the interns at St. Luke's watched in the dormitory. In that story, the young neurosurgeon attended this poor child and watched helplessly his deterioration and ultimate death like the fate of a snow flake. These were the stories of 40 years ago, way before personal computer was even imaginable. Now, I have to ask myself "Have we made any progress in the outcome for children with these dreadful brain tumors?"

Following my 2-year internship, I was accepted by Professor Satoshi Matsumoto to become a neurosurgery resident and Ph.D. Candidate. Matsumoto had just arrived to Kobe as the chairman of newly established Department of Neurological Surgery. When I heard the news that Matsumoto was to be the inaugural chairman of neurosurgery, I had no hesitation to return to Kobe. Prior to that time, I researched and learned that he was a trained pediatric neurosurgeon, the first of its kind in Japan. At Kobe University, I spent my time carrying on both clinical duties and hydrocephalus experiments under his guidance. During that time, my interest in pediatric neurosurgery grew, but most of the cases I took care of were adult aneurysms and brain tumors. Two years later, Professor Matsumoto arranged my residency training at Northwestern University through his close friend Professor Anthony Raimondi. Since my time at St. Luke's, I always wanted to study at the best center in the USA. The dream came true and I started my residency in Chicago in July 1974. Before leaving to Chicago, I read Raimondi's textbook Pediatric Neuroradiology and Matson's Neurosurgery of Infancy and Childhood, which were the only available textbooks for pediatric neurosurgery at that time.

In Chicago, Professor Raimondi kept me at Children's Memorial Hospital for two and a half years of my 6 years residency for further exposure to pediatric neurosurgery. Additionally, I had a 6-month rotation through Pediatric Neurology at Children's which was an absolute delight. During that time, I learned how to examine neonates and infants of which I essentially had no previous experience. In 1978, while I was chief resident at Children's, Raimondi offered me an attending job at Children's Memorial Hospital and Northwestern. I married Kathryn Bel Morley just before the completion of my residency at the end of June 1980, and then, we headed to New York, New York which was our destination and honeymoon. I spent a 1 year of Cancer Fellowship at Memorial Sloan-Kettering Cancer Center. In July 1981, I returned to Chicago and joined my practice with Raimondi, McLone, and Yoon S. Hahn at the Children's Memorial Hospital. Since then, I have had multiple partners who have come and gone except for Dave McLone who continues his practice there. It was a great honor for me to be appointed to be his successor as the Chairman of Pediatric Neurosurgery at Children's Memorial Hospital after Dave relinquished the position in 2001.

Upon return to Chicago from New York in 1981, I was so excited to be an attending neurosurgeon at this prestigious institution and was curious for every aspect of pediatric neurosurgery. Gradually, I concentrated my interest toward the care of pediatric brain tumors. Professor Raimondi, then Department Chair of Neurosurgery at Northwestern, appointed me as a Center-wide Neuro-oncologist at Northwestern even though I had little or no contact with adult patients. At Children's Memorial Hospital, recognizing that children with brain tumors deserved more attention, I started Brain Tumor Clinic in 1986, Multidisciplinary Brain tumor Board in 1988, and Falk Brain Tumor Research Center in 1997. Together, they became Falk Brain Tumor Center. During over 30 years at Children's Memorial, I was involved in the care of nearly 2,400 infants and children with brain tumors. When I started my practice, the annual number of brain tumor patients was only 25 . However, over 30 years, it has increased by $4-5$-folds (Fig. 1). I am not sure of the cause of this steady increase of pediatric brain tumors, perhaps due to improved diagnostic methods, awareness of brain tumors among pediatricians, expansion of our market share, or some sort of environmental factors.

Since I started my training in neurosurgery, I have witnessed and enjoyed terrific advancement in technology. Before CT in the 1970s, we, neurosurgery residents at Children's Memorial, 


\section{Annual \# of Pediatric Brain Tumors over 3 Decades 2398 Children with CNS tumors}

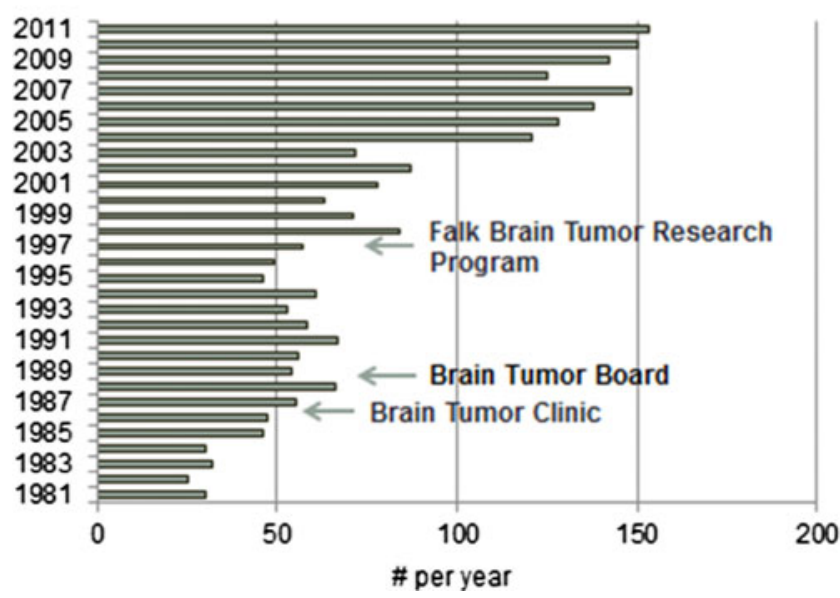

Fig. 1 Annual number of patients with brain tumors over 30 years treated at Children's Memorial Hospital from 1981 to 2011. There were 2,398 infants and children. Note steady increase in numbers

did a lot of pneumoencephalography and angiography under sedation even for young infants. I was trained to perform carotid and brachial angiography in Japan and Chicago, but later learned how to perform femoral catheterization and angiography. I enjoyed performing angiography and its interpretations, then. Today's patients are fortunate to not have to undergo these invasive studies. Then, we were very meticulous about indication of these invasive tests before CT era. Careful history taking and neurological examinations were mandatory. Now-a-days, the brain tumor diagnosis is done readily; a technician would call me from $\mathrm{CT}$ or MR room "Hey, Dr. T, come on over here, here is a huge tumor." CTA and MRA provide refined vascular anomalies without invasive testing. Not only refined anatomical images are seen but also functional localizations by functional MRI and diffusion tensor imaging are readily available. New devises and technologies of neuroradiology field aid us in the operating room as well. Image-guided neuro-navigational system has been widely used, as well as replaced intraoperative ultrasonography that we started to use 30 years ago [1]. We continue to use intraoperative ultrasound from time to time. Vascularity of vascular lesions is effectively reduced by interventional neuroradiologist, now using Onyx [2].

It was only in the late 1960s when surgical microscope became available, but we have seen much advancement in microneurosurgery since then. Surgical laser in the 1970s and ultrasonic aspirator in the early 1980s changed the technique of tumor resection from delicate parts of the brain and spinal cord. Over the past 20 years, with improved endoscopic technology, more and more cases have been managed by so-called minimally invasive neurosurgery. Endoscopic third ventriculostomy largely took over the management of obstructive hydrocephalus [3]. Thanks to the development of advanced instrumentation, some of the small intraventricular tumors can be removed by neuroendoscope without craniotomy. Also, we have noted great progress in pediatric anesthesia and critical care which has provided us improved support in dealing with young patients' brain surgery and postoperative care. When I was a resident in the 1970s, it was not uncommon to experience cardiac arrest during brain tumor resection in children, resulting in the need for CPR.

We have done a better job in resecting tumors and even massive cerebral hemispheric tumors have been resected [4]. Large extremely vascular choroid plexus papillomas in newborn were resected successfully in spite of excessive blood loss [5]. Regrettably, however, I lost three young patients intraoperatively during my career as an attending surgeon: a newborn with massive posterior fossa teratoma, a 3-monthold infant with large hemispheric choroid plexus carcinoma, and a 3-year-old boy with a massive third ventricle astrocytoma. The last two had sudden cardiac arrest following tumor resection just before wound closure. I am still puzzled about the exact cause of their cardiac arrest.

We have witnessed advancement in treating children with brain tumor in other medical fields as well. One of them is marked advancement in radiation oncology. There are big shifts from classic orthogonal irradiation to image-guided irradiation such as 3-D conformal, IMRT, proton radiation and stereotactic radiosurgery.

As a neurosurgeon, I always wanted to irradiate the tumor bed before wound closure. Late in the 1990s, a portable photon radiation system was used by directly placing the tip of the probe into the tumor. It was primarily practiced for metastatic cancer. The same unit was used but with an applicator that fits to the tumor resected cavity (INTRABEAM system) (Fig. 2). We conducted a prospective study of intraoperative radiation therapy (RT) to the tumor resected cavity. It started in 2001 as a phase 1 study, and it included posterior fossa tumor as well. We had a few terrific cases, particularly those of recurrent ependymomas [6]. Partly due to conflict with national protocol, the accrual of patients for INTRABEAM trial was slow, and we treated only 25 children over a 10 years' time. However, ultimately I noted the limitation of this therapy because of unreliable dosimetry distribution along the tumor resected cavity wall, the difficulty to bring it into deep seated tumor bed through narrow opening, and the lack of response of diffuse infiltrating tumor such as glioblastoma.

Chemotherapy has gained recognition for pediatric brain tumor management since the 1980s. Various chemoagents have been developed and used often with a combination of multiple agents such as MOPP, eight in one chemotherapy by Children's Cancer Study group, and baby POG protocol by Pediatric Oncology Group. Over three decades, we have seen terrific responses of germ cell tumors (except for teratomas) to chemotherapy. Chemotherapy contributed to the improvement and quality of lives of children 
Fig. 2 INTRABEAM system (a). Intraoperative photograph showing irradiation to the tumor resected cavity following a removal of recurrent posterior fossa ependymoma (b)
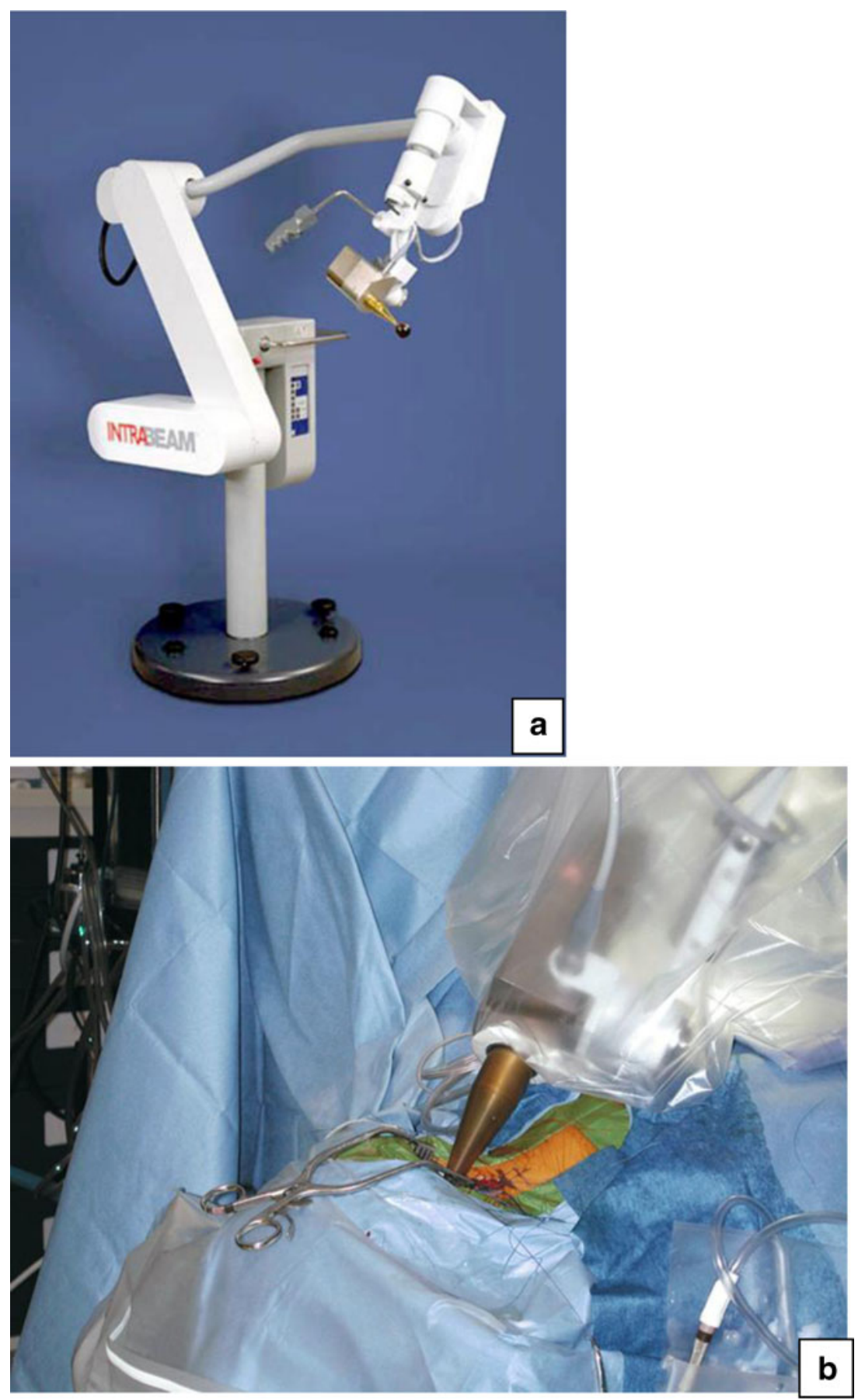

b with medulloblastomas and also even those with benign unresectable astrocytomas. More recently, infantile tumors are treated with high-dose chemotherapy with stem cell rescue, avoiding or delaying RT. Thanks to the recent advancements in cancer biology, molecular targeted therapies have been exercised largely on an experimental basis for the past 10 years. These small molecule agents or monoclonal antibodies affect more specific tumor cells and are less toxic to normal cells.

I used to resect chiasmal/hypothalamic astrocytomas and regrettably often caused visual, endocrine, and neurological problems in infants and children. Not many people believed chemotherapy worked for benign astrocytomas until the late 1980s. However, chemotherapy became the first line of treatment for these unresectable benign astrocytomas, since then. Skeptically, we started this approach in 1988, but behold, we attained $63 \%$ recurrence-free survival at 5 years [7]. Recent national study shows the result of 5 -year eventfree survival as $45 \pm 3.2 \%$ following chemotherapy alone, less than we experienced [8]. But it is still better not to cause surgical complications or radiation side effects in infants. At least, chemotherapy provides some relief for the infant and young child. It is delightful to see some children appear to 
be cured with chemotherapy. Discouragingly, however, it is not uncommon to see a regrowth of initially responded tumor a few years after discontinuing the treatment.

I wanted to improve the drug delivery system and have been long interested in interstitial chemotherapy, a direct administration to the tissue of brain tumors. Thus, I wrote a review paper regarding this subject in 1991 for the preparation of my future translational research and ultimate clinical applications [9]. This convection enhanced interstitial chemotherapy provides higher drug concentration while circumventing the blood brain barrier through the extracellular spaces in the central nervous system. This approach was intended to be applied to intrinsic unresectable tumors.

During my residency, I spent my time reviewing charts of children with brain tumor at Children's Medical Record while taking every other night on call. I was mesmerized doing the clinical review of these children, the majority of whom I never met, yet I started to remember their names and they felt like my own patients. Reviewing a ton of charts provided me information as to how they presented, how they were diagnosed and treated, and what their outcomes were. The database I collected during that time led to subsequent publications in the late 1970s and early 1980 s.

One of those publications is a paper concerning precraniotomy shunts for hydrocephalus secondary to posterior fossa tumors [10]. Hydrocephalus due to infratentorial tumors was initially treated with a VP shunt, followed by tumor resection in sitting position which was Dr. Raimondi's idea. We waited 7 to 14 days until papilledema was resolved before posterior fossa craniotomy, which was also his idea instead of craniectomy which was popular at that time. This paper was unique because it was one of the rare papers providing information as to when the papilledema subsides. Nonetheless, I abandoned this precraniotomy shunt approach. Since 1986 until now, I have practiced ventriculostomy under the same general anesthesia for posterior fossa craniotomy in prone position [11]. The main concerns of precraniotomy shunting for a posterior fossa tumor are the requirement of two general anesthesia and not all patients necessarily need a shunt after successful tumor resection. Also, post-shunt upward herniation is a real concern. This upward herniation is usually seen in younger patients with medulloblastoma and ependymoma associated with advanced hydrocephalus and occurs in 3-6\%. If it occurs, it is absolutely devastating (Fig. 3).

Another subject that drew my interest was brain tumors affecting infants $[12,13]$. When compared the tumors during the first year of life treated between 1952-1984 [13] and more recent $1988-2010$, it was only 1.8 per year in the earlier experience while it was 5 per year in the later which I presented at the annual meeting of ISPN in Goa, 2011 (Table 1). New pathological entity of atypical teratoid rhabdoid tumor (ATRT) takes up a large part of malignant tumors, which were very likely included in medulloblastoma and PNET in the past.

Academic neurosurgeons must make an effort to contribute to the advancement in patient care and scientific discovery in their own subspecialty. So, I did my share or have tried to do so for pediatric neurosurgery and pediatric brain tumor in particular. Here, I would like to share my own experience with you by showing some of the brain tumor research work that I was involved in. Because of the limited time frame of this presidential address, I would like to go over only a representative portion of posterior fossa tumors: medulloblastoma, posterior fossa ependymoma, and brain stem tumor.

\section{Medulloblastomas}

Early in my neurosurgical career, medulloblastoma attracted my interest the most. It was because Dr. Raimondi invited me to write a chapter of "IVth Ventricle Tumor" when I was a resident for a new textbook Pediatric Neurosurgery [14]. Raimondi and I in 1979 published a paper emphasizing the importance of radical resection of medulloblastoma [15]. Prior to that time, biopsy followed by RT was an acceptable treatment. The total resection group showed a better survival: $42 \%$ after resection and $34.5 \%$ after incomplete resection at 5 years. Please note they were treated in the pre-CT era so that we do not know the time of recurrence, and the only thing we knew then was dead or alive for survival statistics.

Medulloblastoma, however, is a challenging tumor to remove because of its proximity to the brain stem and cerebellar peduncle. However, aggressive tumor resection can lead to increased morbidity, particularly cerebellar mutism. A recent data of my own, that were presented at ISPN [16], showed that the incidence of cerebellar mutism among 100 consecutively treated medulloblastomas was $24 \%$; it appears to be common among children whose medulloblastoma has brainstem involvement (32\%) or subtotal resection group (34\%) than those without brainstem involvement (20\%) or total or near total resection (19\%). A similar observation was presented by Children's Oncology Group (COG) prospective studies in 2006 , in which $107,24 \%$, of 450 children with medulloblastoma developed postoperative cerebellar mutism [17]. It was comforting to note that I am not the only guy who is experiencing such a high complication rate after all. Still the exact cause of cerebellar mutism is not known. Hopefully, we can identify the causes by DTI and find a method to avoid this devastating complication.

We learned several things during follow-up of the radiation sequelae on medulloblastoma in children. They are psychomotor delay, second cancer, endocrinopathy, vasculopathy, hearing loss, etc. $[18,19]$. Raimondi and I wrote in 1979 one of the earliest papers, warning about the concern of detrimental effects 
Fig. 3 Non-enhanced head CT axial view showing a large partially calcified tumor in the cerebellum and advanced hydrocephalus in an 8-monthold infant (a). The infant suddenly developed respiratory arrest and coma about $10 \mathrm{~h}$ after CSF diversion. Non-enhanced head CT axial view showing upward herniation with intratumoral hemorrhage and collapsed ventricles (b)
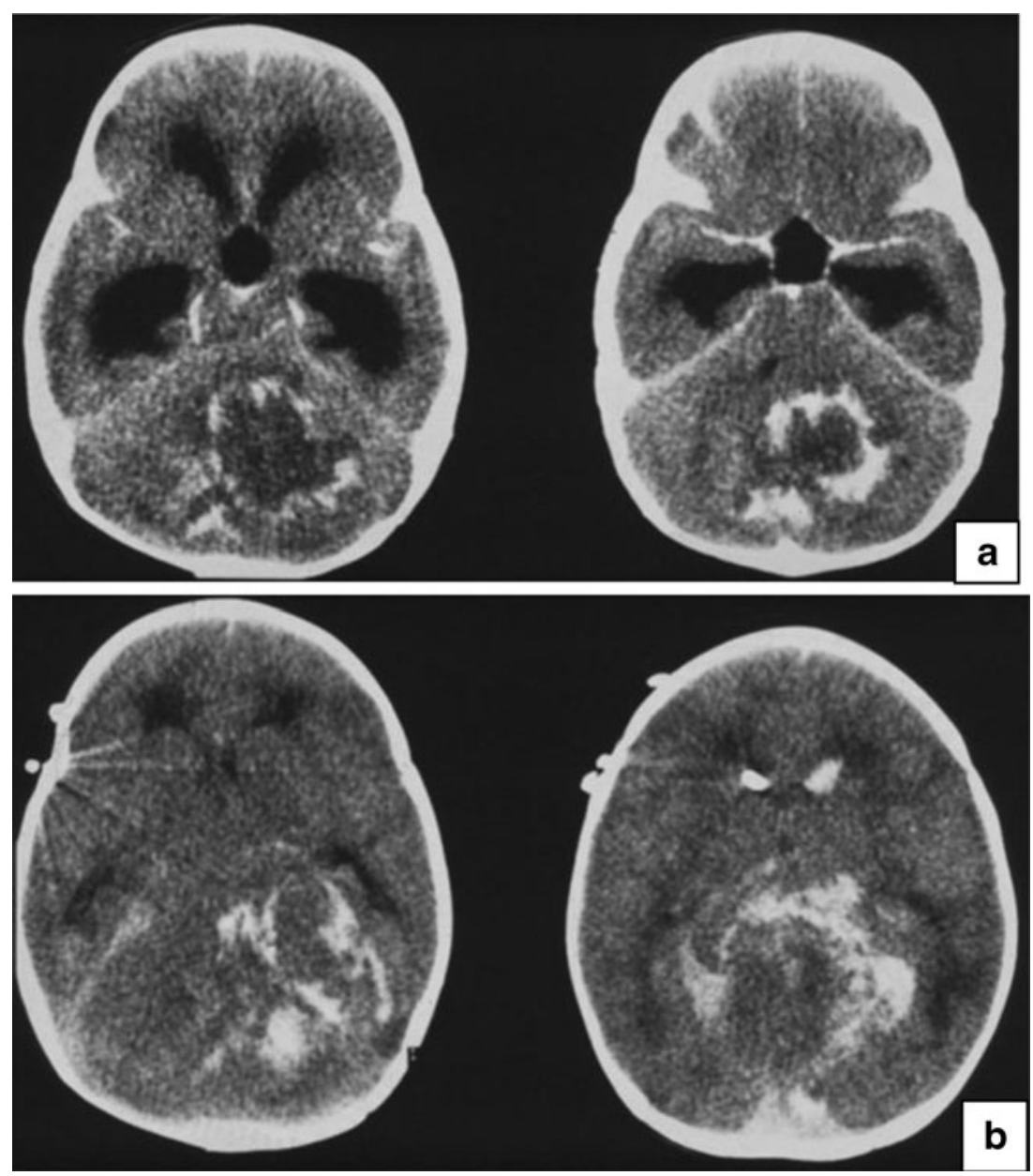

of ionizing radiation to the developing CNS among children with medulloblastoma [20]. I think this is one of the most important papers that I was involved in. A comparison was made between medulloblastoma children who received RT (the

Table 1 Infantile brain tumor ( $<12$ months)

\begin{tabular}{lll}
\hline & $1952-1984^{\mathrm{a}}$ & $1988-2010^{\mathrm{b}}$ \\
\hline Astrocytoma & 11 & 48 \\
ATRT & 0 & 13 \\
Medulloblastoma/PNET & 14 & 12 \\
Choroid plexus papilloma & 10 & 8 \\
Ependymoma & 3 & 6 \\
Glioblastoma & 6 & 6 \\
Hamartoma & 0 & 5 \\
Germ cell tumor & 3 & 3 \\
Hemangioma of infancy & 0 & 3 \\
Craniopharyngioma & 2 & 0 \\
Others & 9 & 6 \\
& 57 (1.8/year) & 111 (5/year) \\
\hline
\end{tabular}

${ }^{a}$ Tomita and McLone [13]

${ }^{\mathrm{b}}$ Tomita T, ISPN Goa, 2011 radiation dose to whole brain, 35 to $42 \mathrm{~Gy}$ ) and cerebellar astrocytoma children without RT. The IQ was far worse among children with medulloblastoma. In the same year, Jean François Hirsch from Paris published a similar observation [21].

Because of these observations, after discussing with our radiation oncologists, we adopted a reduced craniospinal irradiation (CSI) dose to 25 Gy and published the data in 1986 [22]. We found there were no case mortalities during the follow-up period of 24-67 months among the totally resected group even though the dose was low. Both POG and CCG incorporated this reduced-dose CSI RT protocol for the lowstage medulloblastoma and compared two groups with CSI dose 23.4 vs. $36 \mathrm{~Gy}$, (randomizing 126 patients) without chemotherapy [23]. Much to my dismay, however, it was noted that the group with reduced dose showed higher early relapse rates and disseminations, and the study was closed in the very early stage. The data showed $67 \%$ event-free survival at 5 years among patients with standard radiation dose, whereas eligible patients receiving reduced-dose CSI had $52 \%$ event-free survival at 5 years $(P=0.080)$. Although long-term event-free survival rates showed no statistical difference, it was concluded "The 5 -year EFS for patients receiving reduced-dose irradiation 
is suboptimal, and improved techniques and/or therapies are needed. Chemotherapy may contribute to this improvement."

Together with Dr. Marianne Marymont of Northwestern Radiation Oncology, we treated patients with medulloblastoma with hyperfractionated RT, twice a day radiation, as a pilot study and published the results in 1996 [24]. These patients were treated with RT alone. This was a pilot study where we noted that it was feasible but very labor intensive as you can imagine, so we abandoned this approach and then long forgot it. However, I was surprised to find these recent publications using hyperfractionated radiation for medulloblastomas. A French study using 36 Gy to CSI and 68 Gy to posterior fossa without chemotherapy attained $75 \% 6$-year event-free survival rates [25]. They observed annual full scale IQ decline was 2 points over a 6-year period. The German study published this year showed that 5 -year EFS was $77 \pm 4 \%$ in the standard RT group and $78 \pm 4 \%$ in the hyperfractionated RT group [26]. The German study using adjuvant chemotherapy concluded no difference in the survival rates in standard and hyperfractionated groups.

Recent data of national protocols with RT and chemotherapy are as follows: 5- and 10-year event-free survivals among standard risk medulloblastoma were $81 \pm 2$ and $75.8 \pm 2.3 \%$ and overall survivals were $87 \pm 1.8$ and $81.3 \pm 2.1 \%$ [27]. Even children with high-risk medulloblastoma attain $59 \pm 10$ to $71 \pm$ $11 \% 5$-year event-free survival [28]. When compared with our data published more than 30 years ago with only $35 \%$ overall survival rate, it shows that we have come a long way.

I was engaged in several biological studies. Medulloblastomas were known to disseminate through the CSF pathway. Chang's classification published in 1969 remains active, but it is a postoperative evaluation. I thought it was imperative to know the incidence of spontaneous dissemination of medulloblastoma. Therefore, my idea was to harvest and test the samples of the CSF and arachnoid membrane from the cisterna magnum before tumor manipulation at the time of posterior fossa craniotomy [29]. Subsequent data with greater number of patients than previous publication showed that 25 of 56 CSF cytologies and 23 of 57 arachnoid biopsies were positive, and $35(56 \%)$ of 63 tested were positive for tumor dissemination [30]. More recently, Souweidane et al. performed a similar study and noted that arachnoid infiltration and CSF cytology were found in 20.0 and $44.8 \%$, respectively, for medulloblastoma/pineoblastoma (primitive neuroectodermal tumor) [31]. Therefore, it is well justified to treat the entire neuroaxis of medulloblastoma patients.

In the middle of the 1980s, we reviewed with Dr. Katsushi Taomoto, a visiting neurosurgeon from Kobe, our archival tissues of medulloblastoma and noted that certain histological features do correlate with the patient's outcome. It was published in 1987 [32]. Around that time, only classic and desmoplastic types were common prognostic indicators. Our study disclosed pleomorphism, high nuclear/cytoplasmic ratio, mitotic index, and high vascularity indicating poorer patient outcome. Our observation was similar as later findings of anaplastic and large cell medulloblastomas sub-classified by "2007 WHO Classification of CNS Tumours" to be high-risk medulloblastomas.

In the 1980s, in the pediatric oncology arena, DNA ploidy was considered to be an important prognostic factor for common childhood cancers such as neuroblastoma and lymphoblastic leukemia. The group of DNA aneuploidy fared better than diploid type among these tumors. Because of curiosity as to if medulloblastoma follows the same trend, we tested the significance of DNA ploidy for prognosis of medulloblastoma children using flow cytometry. This idea was brought up by then Northwestern resident, Herb Engelhard. I asked then visiting neurosurgeon Dr. Masaharu Yasue from Jikei University in Tokyo to conduct research on this subject at Kenneth Bauer's flow cytometry lab at Northwestern. The DNA ploidy results were compared with survivals of medulloblastoma children who were treated with postoperative RT alone, not with chemotherapy. It was noted the group with DNA aneuploidy showed significantly better survival [33, 34]. However, later study with DNA ploidy and MDR gene expression showed different results; we tested 29 patients with medulloblastoma treated from 1987 to 1991 who received both postoperative RT and chemotherapy. The results of this study published in 1995 showed neither DNA ploidy nor the extent of resection influenced the survival [35]. However, MDR expression, which is present in $55 \%$ of the patients, showed poor outcome $(P=0.007)$, and statistically significant correlation was noted between MDR expression and prognosis.

Subsequently, with more advanced cytogenetic studies, we have done cytogenetic studies on a variety of pediatric brain tumors. We noted in 1998 that clonal abnormalities are associated with poor prognosis. Medulloblastoma has been one of the most studied pediatric cancers in regard to cytogenesis and its molecular characteristics [36]. More and more cytogenetic studies and molecular biological studies have been done extensively for medulloblastomas over the past two decades. More recently in 2011, four distinct molecular variants among medulloblastomas were classified based upon gene expression profiles and DNA copy number aberration, which reflected patients' prognosis [37]. These new findings will very likely be used for future development of national protocol. I am sure more molecular-based findings and therapeutic options are on the horizon.

\section{Posteior fossa ependymoma}

Over the years, we found posterior fossa ependymomas are more difficult to manage. I still remember Luis Schut mentioned at one of the pediatric meetings in the early 1980s that he 
would rather see a child with medulloblastoma than ependymoma. Although I published a paper 1988 entitled "Benign Ependymomas of the Posterior Fossa in Childhood" [38], the treatment results are quite unsatisfactory. The term "benign" should not be there in the title of the paper. I emphasized that total resection remains the way to deliver the patient's best outcome. However, it is often very difficult to achieve due to cranial nerve and brain stem involvement [39]. Previously, we could not find statistical correlation between DNA index, patient outcome, and histology though ependymomas are morphologically highly variable tumors of potential aggressiveness without valuable prognostic markers based upon histological and DNA flow cytometric studies [40] However, COG collected 96 posterior fossa ependymomas treated from 1990 to 2000 and concluded anaplastic variants indeed show poor prognosis [41]. According to this report, nearly half of the patients are
Fig. 4 Brain stem tumor model in rat; sagittal section (left) and axial section (right) (a). An Aztec mini-osmotic pump is implanted for intracerebral chronic infusion of chemotherapy (b). In vivo bioluminescence images in rats showing active tumor in rat's brain (c)
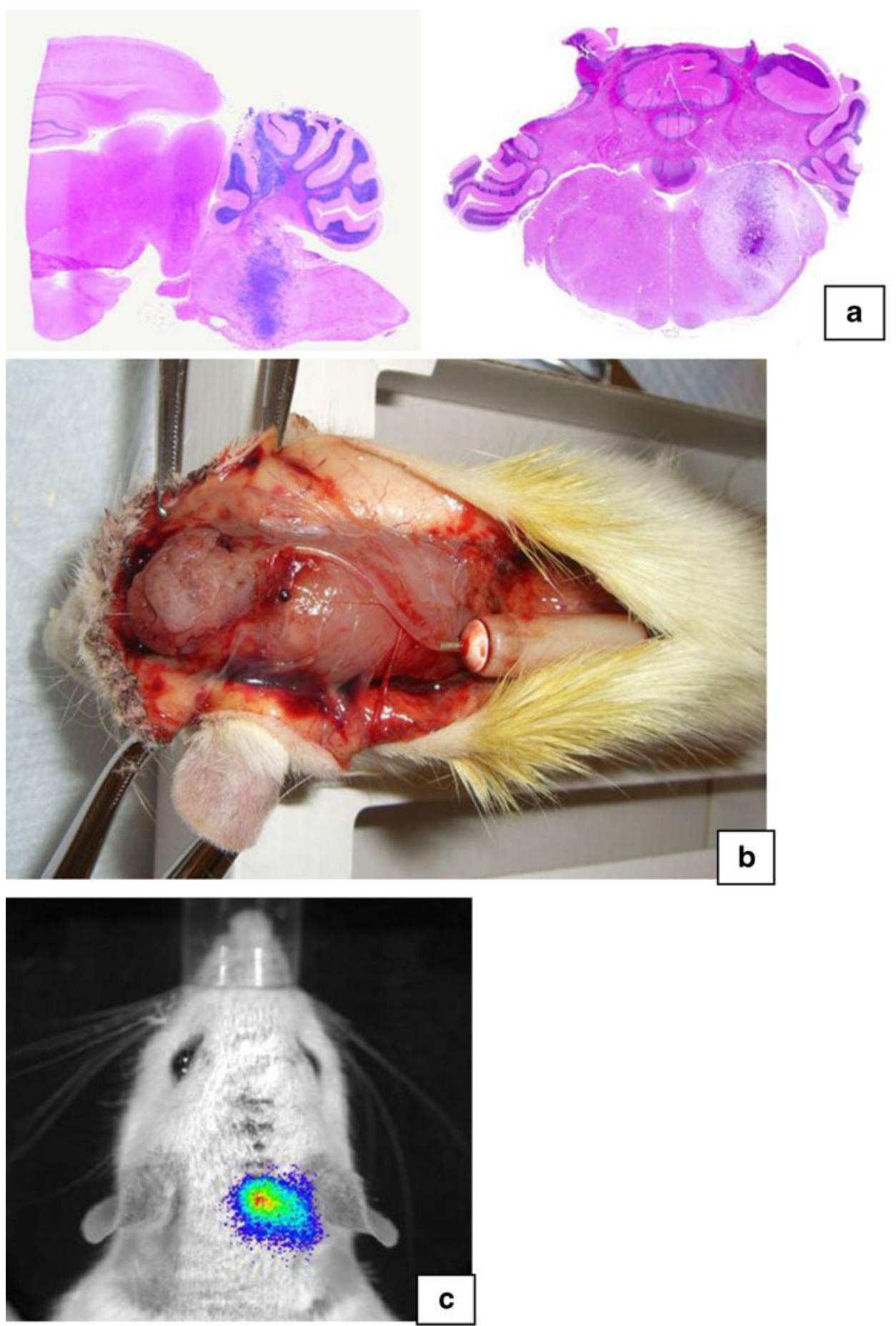
younger than 3 years, had gross total resection, and had anaplastic variants. Even the lower risk group showed the 5-year EFS at barely $40 \%$.

Chemotherapy has been used for young patients with ependymoma with unsatisfactory responses, which has been well recognized. At our lab, Dr. Pauline Chou studied MDR expression. We found a much larger number, $95 \%$, of the ependymomas express MDR gene [42]. It is much higher than medulloblastomas and explains the relative lack of chemosensitivities among ependymomas. A COG study showed that of 35 patients, 14 (40\%) demonstrated complete response, 6 (17\%) partial response, 10 (29\%) minor response or stable disease, and $5(14 \%)$ progressive tumor growth following cisplatin-based chemotherapy [43].

We have investigated epigenetic roles on tumor onset and progression for ependymomas at our Falk Brain Tumor Research Lab. Histone modification and DNA methylation resulting in alteration of the gene expression have been investigated. Preliminary studies indicate a decrease in global levels of methylation in ependymomas, together with further reduction in methyl cytosine levels after exposure to chemotherapy [44]. When we observed human ependymoma tissue samples for global Alu methylation profile, methylation levels diminish when the ependymoma becomes more aggressive. Our data indicate that chemotherapy may induce epigenetic alterations that in turn cause the tumor to be more aggressive, but this result is tentative and obviously further testing is needed.

More recently, we have looked into the expression and role of microRNA (miRNA) in various tumors. The miRNAs are non-coding RNAs that can block mRNA translation and affect mRNA stability. Changes in the expression of miRNAs have been correlated with many human cancers. We have noted tumor-specific expression of miRNAs among pediatric brain tumors [45].

We tested miRNA contribution to the prognosis for a variety of pediatric brain tumors. We have examined the expression of miRNAs in ependymomas to identify molecular markers of value for clinical management. miRNAs are non-coding RNAs that can block mRNA translation and affect mRNA stability. We have identified certain miRNAs that are over-expressed or down-regulated in ependymomas [46]. The miRNA expression profiles were then correlated with tumor location and histology and uncovered specific miRNAs which correlate with a worse prognosis. We have uncovered associations between the expression of specific miRNAs which portend a worse prognosis. A cluster of miRNAs on human chromosome $14 \mathrm{q} 32$ is associated with recurrence. A higher expression of miR-432, miR-411, miR 376-a, miR-381, and miR-487b was associated with a lower recurrence-free probability, while with miR-203, we observed that its lower expression correlated with a trend to develop recurrences of ependymoma. Also we studied ATRT, in which overexpression of miR221/222 is noted [47,48]. They may be contributing to oncogenesis and progression of ATRT. Thus, we reason that anti-miRNA therapy might be an option for the treatment of these very aggressive and unresponsive tumors.

\section{Brainstem tumors}

I wrote a paper in 1984, entitled "Brain Stem Gliomas in Childhood: Rational Approach and Treatment" [49]. The term "rational" at that time meant "do not do the biopsy for diffuse intrinsic pontine tumors (DIPG)." The rationale is that the obtained sample does not necessarily represent the entire picture of the tumor due to its heterogeneity. No biopsy has been recommended or practiced for typical DIPG in North America since. However, based upon neuroimaging characters, these brain stem tumors were classified into several types like Fred Epstein and Harold Hoffman did [50]. I tried surgical options in certain groups of brain stem tumors primarily dividing these into pontine and extra-pontine tumors; the latter include the cerebellar peduncle lesions [51], exophytic IV ventricle astrocytomas [52], medullary and cervicomedullary astrocytoma, and midbrain/cerebral peduncle tumors [53] . Because of uniformly dismal results of DIPG after conventional radiotherapy, hyperfractionated RT was done as a pilot study conducted late in the 1980s [54]. This approach was declared to be ineffective and abandoned. A study published by COG using conventional RT with chemotherapy showed no difference 12 years later.

Only late in 2012 a multicenter cooperative trial of active tissue biopsy of DIPG began to identify gene expression of MGMT and EGFR. Based upon the gene expression, the treatment strategy is altered by choosing different targeted therapy. Hopefully, a breakthrough will be found for this dreadful disease.

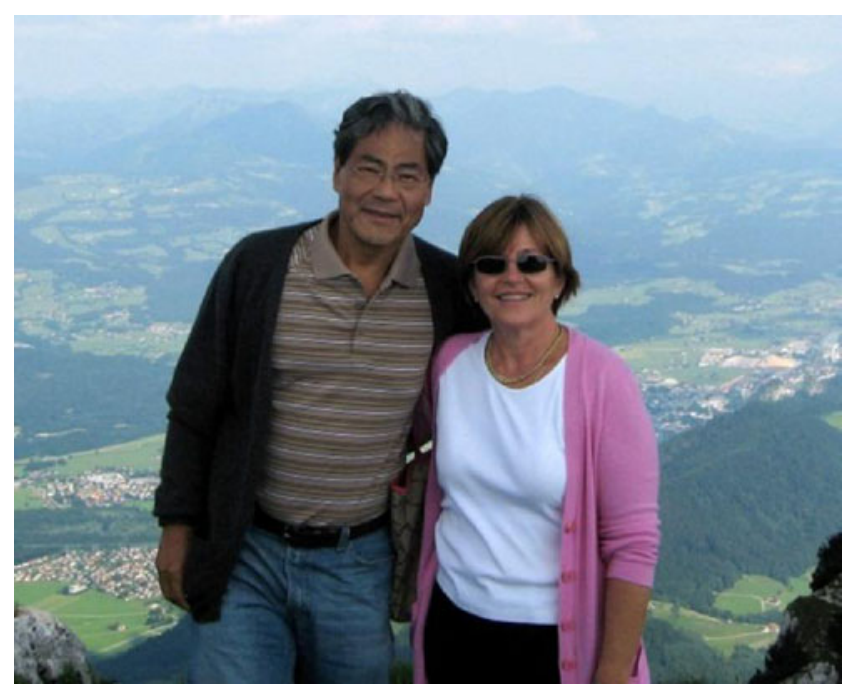

Fig. 5 A picture of Tadanori and Kathryn Tomita 
In order to explore novel therapeutic methods, we started a project of interstitial chemotherapy for DIPG [9]. In my lab, Drs. Yuichi Tange and Akihide Kondo from Juntendo University, Tokyo made animal brain tumor models in rats for a convection enhanced drug delivery system (Fig. 4a) [55, 56]. Following a relentless effort, we successfully developed a tumor model and a chronic convection enhanced delivery system using an Aztec mini-osmotic pump (Fig. 4b). In order to see the tumor progression in vivo, a brainstem tumor model using bioluminescence glioma cells was established. The progression of tumor growth in the brain stem was observed in vivo bioluminescence images in rats (Fig. 4c). We tested the efficacy after interstitial treatment with various chemotherapy agents including carboplatin. Dr. Guifa Xi, who succeeded this research project in my lab, treated them with vincristine, and the results of efficacy and toxicity were published in 2011 [57]. For that study, first, vincristine toxicities after direct injection to the brain stem in a rat were tested to optimize the dosage [58]. Subsequently, rat brain stem glioblastoma was treated with vincristine administered through convection enhanced interstitial injection comparing with control, intravenous, and intraperitoneal injections. Only the convection enhanced delivery group had survival of more than $50 \%$ while all others died within 3 weeks. The convection enhanced interstitial delivery appears to be feasible in animals; however, it is too early to apply this method to the human. Clearly, the drug and dosage selections need to be finalized.

\section{Summary}

I have given you my humble experiences of the managements of representative pediatric brain tumors including various aspects, from clinical to basic research. There is no question in my mind that we have made great strides in diagnosing and treating pediatric brain tumors over the past four decades. Look at medulloblastoma! We are now able to cure $80 \%$ of these children. Unfortunately, however, not necessarily all children live. Still these children with medulloblastoma need cytotoxic therapies which unavoidably cause short or long-term side effects [59]. Could we cure Koh-chan with recurrent craniopharyngioma or a child with DIPG seen 40 years ago in the soap opera? I am afraid the answer is "no." I did not mention in this presentation about the treatment of craniopharyngioma which still remains controversial in terms of extent of resection: total resection vs. limited resection followed by RT [60]. How about DIPG? There have been absolutely no breakthroughs. Insanity, as Albert Einstein once said, "is doing the same thing again and again and expecting different results." Progress in molecular biology which enables us to understand tumor origin, character, genetic, and epigenetic features is breathtaking. It is our obligation to identify the safest and most effective therapy based upon current scientific research.

We know that today's acceptable therapy will likely becomes tomorrow's obsolete. As seen in this reflection of a portion of my life work, some of observations or ideas were later proven to be wrong while others have led to newer treatment concept. Einstein also said, "Anyone who has never made a mistake has never tried anything new." The problem in our profession, however, is that we cannot make mistakes and screw up a child's brain. So, it is so important to conduct careful investigation in the laboratory and develop long-range plans and research/clinical protocol.

I still have a lot of ideas and dreams for a better future for the pediatric neurosurgery patient. Pediatric neurosurgery, for me, encompasses science, art, and humility. I love my profession, and I am honored and privileged to take care of another person's precious child.

I appreciate the members of ISPN who supported me as your 40th president. And the last but not least, a special thanks to Kathy, my wife of 31 years, who has been a terrific partner, supporting and caring for me in very difficult times (Fig. 5). She has raised our three wonderful sons, Tadaki, Kenji, and Dan, while I was busy, working late most of the time. They are the best of my life and have made my life very rich. I am very proud to call myself "a pediatric neurosurgeon," but I am more proud to be their father and her husband. Without Kathy's presence and support, I would not be here delivering this presidential address. Thanks Kathy.

Open Access This article is distributed under the terms of the Creative Commons Attribution License which permits any use, distribution, and reproduction in any medium, provided the original author(s) and the source are credited.

\section{References}

1. Shkolnik A, Tomita T, Raimondi AJ, Hahn YS, McLone DG (1983) Work in progress. Intraoperative neurosurgical ultrasound: localization of brain tumors in infants and children. Radiology 148:525-527

2. Soltanolkotabi M, Schoeneman ME, Alden TD, Hurley MC, Ansaril SA, DiPatri AJ, Tomita T, Shaibani A (2012) Safety and efficacy of onyx embolization of intracranial arteriovenous malformations in pediatric patients. J Neurosurg (Pediatr) 71(4):773-784

3. Navarro R, Gil-Parra R, Reitman AJ, Olavarria G, Grant JA, Tomita $T$ (2005) Endoscopic third ventriculostomy: early and late complications and their avoidance. Childs Nerv Syst 22:506-513

4. Tomita T, Bailes J, McLone DG (1987) Giant cerebral hemispheric tumors in childhood. Concept Pediatr Neurosurg 7:58-71

5. Tomita T, Naidich TP (1987) Successful resection of choroid plexus papillomas diagnosed at birth: report of two cases. Neurosurgery 20:774-779 
6. Kalapurakal JA, Goldman S, Stellpflug W, Curran J, Sathiaseelan V, Marymont MH, Tomita T (2006) Phase I study of intraoperative radiotherapy with photon radiosurgery system in children with recurrent brain tumors: preliminary report of first dose level (10 Gy). Int J Radiat Oncol Biol Phys 65(3):800-808

7. Silva MM, Goldman S, Tomita T (2000) Optic pathway/hypothalamic gliomas in children under three years of age: the role of chemotherapy. Pediatr Neurosurg 33:151-158

8. Ater JL, Zhou T, Holmes E, Mazewski CM, Booth TN, Frever DR, Lazarus KH, Packer RJ, Prados M, Sposto R, Vezina G, Wisoff JH, Pollack IF (2012) Randomized study of two chemotherapy regimens for treatment of low-grade glioma in young children: a report from the Children's Oncology Group. JCO 30:2641-2647

9. Tomita T (1991) Interstitial chemotherapy for brain tumors: review. J Neuro Oncol 10:57-74

10. Raimondi AJ, Tomita T (1981) Hydrocephalus and infratentorial tumors. Incidence, clinical picture and treatment. J Neurosurgery 55:174-182

11. Tomita T, Rosenblatt SS (1991) Management of hydrocephalus secondary to posterior fossa tumor in childhood. In: Matsumoto S, Tamaki N (eds) Hydrocephalus: pathogenesis and treatment. Springer, Tokyo, pp 306-310

12. Raimondi AJ, Tomita T (1983) Brain tumors during the first year of life. Child's Brain 10:193-207

13. Tomita T, McLone DG (1985) Brain tumors during the first 24 months of life. Neurosurgery 17:913-919

14. Tomita T, Raimondi AJ (1982) IV ventricle tumors. In: McLaurin R, Reigel D, Hendrick B (eds) Pediatric neurosurgery. Grune and Stratton, New York, pp 383-393

15. Raimondi AJ, Tomita T (1979) Medulloblastoma in childhood: comparative results of partial and total resection. Child's Brain 5:310-328

16. Tomita T, Goldman S, Marymont M, Keating G, DeLeon G (2003) Childhood medulloblastoma: review of 20 years' experience. Child Nerv Syst 19:623

17. Robertson PL, Muraszko KM, Holmes EJ, Sposto R, Packer RJ, Gajjar A, Dias MS, Allen JC (2006) Incidence and severity of postoperative cerebellar mutism syndrome in children with medulloblastoma: a prospective study by the Children's Oncology Group. J Neurosurg 105(6 Suppl Pediatric):444-451

18. Tomita $T$ (1992) Long term effects of treatment for childhood brain tumors. Neurosurg Clin North Am 3:959-971

19. Grenier Y, Tomita T, Byrd SE, Burrowes DM, Marimond M (1998) Late post-radiation occlusive vasculopathy in childhood medulloblastoma: report of 2 cases. J Neurosurg 89:460-464

20. Raimondi AJ, Tomita T (1979) The disadvantages of prophylactic whole CNS postoperative radiation therapy for medulloblastoma. In: Paoletti P et al (eds) Multidisciplinary aspects of brain tumor therapy. Elsevier, New York, pp 209-219

21. Hirsch JF, Renier D, Czernichow P et al (1979) Medulloblastoma in childhood. Survival and functional results. Acta Neurochir 48:1-15

22. Tomita T, McLone DG (1986) Medulloblastoma in childhood. Results of radical resection and low dose radiation therapy. J Neurosurg 64:238-242

23. Thomas PRM et al (2000) Low-stage medulloblastoma: final analysis of trial comparing standard-dose with reduced-dose neuraxis irradiation. JCO 18:3004-3011

24. Marymont MH, Geohas J, Tomita T, Strauss L, Brand WN, Mittal BB (1996) Hyperfractionated craniospinal radiation in medulloblastoma. Pediatr Neurosurg 24:178-184

25. Carrie C, Grill J, Figarella-Branger D, Bernier V, Padovani L, Habrand JL, Benhassel M, Mege M, Mahé M, Quetin P, Maire JP, Baron MH, Clavere P, Chapet S, Maingon P, Alapetite C, Claude L, Laprie A, Dussart S (2009) Online quality control, hyperfractionated radiotherapy alone and reduced boost volume for standard risk medulloblastoma: long-term results of MSFOP98. J Clin Oncol 27(11):1879-1883
26. Lannering B, Rutkowski S, Pizer B, Gustafsson G, Navajas A, Massimino M, Reddingius R, Benesch M, Carrie C, Taylor R, Gandola L, Björk-Eriksson T, Giralt J, Oldenburger F, Pietsch T, Figarella-Branger D, Robson K, Forni M, Clifford SC, WarmuthMetz M, von Hoff K, Faldum A, Mosseri V, Kortmann R (2012) Hyperfractionated versus conventional radiotherapy followed by chemotherapy in standard-risk medulloblastoma: results from the randomized multicenter HIT-SIOP PNET 4 Trial. J Clin Oncol 30(26):3187-3193

27. Packer RJ, Zhou T, Holmes E, Vezina G, Gajjar A (2013) Survival and secondary tumors in children with medulloblastoma receiving radiotherapy and adjuvant chemotherapy: results of Children's Oncology Group Trial A9961. Neurooncol 15(1):97-103

28. Jakacki RI, Burger PC, Zhou T, Holmes EJ, Kocak M, Onar A, Goldwein J, Mehta M, Packer RJ, Tarbell N, Fitz C, Vezina G, Hilden J, Pollack IF (2012) Outcome of children with metastatic medulloblastoma treated with carboplatin during craniospinal radiotherapy: a Children's Oncology Group Phase I/II study. J Clin Oncol 30(21):2648-2653

29. Tomita T, McLone DG (1983) Spontaneous seeding of medulloblastoma: results of CSF cytology and arachnoid biopsy from the cisterna magnum. Neurosurgery 12:265-267

30. Tomita T, Marymont M, Strauss L, La Marca F (1997) Childhood medulloblastomas: spontaneous disseminations, pattern of recurrences and importance of adjuvant chemotherapy. Neurol Surg Relaz 11:163-168

31. Souweidane MM, Morgenstern PF, Christos PJ, Edgar MA, Khakoo Y, Rutka JT, Dunkel IJ (2009) Intraoperative arachnoid and cerebrospinal fluid sampling in children with posterior fossa brain tumors. Neurosurgery 65(1):72-78

32. Taomoto K, Tomita T, Raimondi AJ, Leestma JE (1987) Medulloblastoma in childhood: histological factors influencing the patients' outcome. Child's Nervous System 3:354-360

33. Tomita T, Yasue M, Engelhard H, Bauer KD, McLone DG, Gonzalez Crussi F (1988) Flow cytometric DNA analysis of medulloblastoma: correlation between DNA ploidy and outcome. Cancer 61:744-749

34. Yasue M, Tomita T, Engelhard H, Gonzalez Crussi F, McLone DG, Bauer KD (1989) Prognostic importance of DNA ploidy in medulloblastoma of childhood. J Neurosurg 70:385-391

35. Chou PM, Reyes Mugica M, Braquin N, Yasuda T, Tan X, Tomita T (1995) Multidrug resistance gene expression in childhood medulloblastoma: correlation with clinical outcome and DNA ploidy in 29 patients. Pediatr Neurosurg 23:283-291

36. Tomita T (1996) Medulloblastoma. In: Youmans JR et al (eds) Neurological surgery (4th ed.). Saunders, Philadelphia, pp 2570-2592

37. Ellison DW, Dalton J, Kocak M, Nicholson SL, Fraga C, Neale G, Kenney AM, Brat DJ, Perry A, Yong WH, Taylor RE, Bailey S, Clifford SC, Gilbertson RJ (2011) Medulloblastoma: clinicopathological correlates of SHH, WNT, and non-SHH/WNT molecular subgroups. Acta Neuropathol 121(3):381-396

38. Tomita T, McLone DG, Das L, Brand WN (1988) Benign ependymomas of the posterior fossa in childhood. Pediatr Neurosci 14:277-285

39. Tomita T (2001) Ependymomas. In: McLone DG (ed) Pediatric neurosurgery. Saunders, Philadelphia, pp 822-834

40. Reyes-Mugica M, Chou PM, Myint MM, Ridaura-Sanz C, Gonzalez-Crussi F, Tomita T (1994) Ependymomas in children: histological and DNA-flow cytometric study. Pediatrc Pathol $14: 453-466$

41. Tihan T, Zhou T, Holmes E, Burger PC, Ozuysal S, Rushing EJ (2008) The prognostic value of histological grading of posterior fossa ependymomas in children: a Children's Oncology Group study and a review of prognostic factors. Mod Pathol 21(2):165-177

42. Chou PM, Barquib N, Yasuda T, Sanz CR, Gonzalez Crussi F, Tomita T (1996) Ependymomas express the multidrug resistance 
gene: immunohistochemical and molecular biologic study. Pediat Pathol Lab Med 16:551-561

43. Garvin JH Jr, Selch MT, Holmes E, Berger MS, Finlay JL, Flannery A, Goldwein JW, Packer RJ, Rorke-Adams LB, Shiminski-Maher T, Sposto R, Stanley P, Tannous R, Pollack IF (2012) Children's Oncology Group. Phase II study of pre-irradiation chemotherapy for childhood intracranial ependymoma. Children's Cancer Group protocol 9942: a report from the Children's Oncology Group. Pediatr Blood Cancer 59(7):1183-1189

44. Xie H, Wang M, de Fatima Bonaldo M, Rajaram V, Stellpflug W, Smith C, Kelly Arndt K, Goldman S, Tomita T, Soares M (2010) Epigenomic analysis of Alu repeats in human ependymomas. Proc Natl Acad Sci 107(15):6952-6957

45. Sredoni S, Huang CC, Bonaldo M, Tomita T (2011) MicroRNA expression profiling for molecular classification of pediatric brain tumor. Pediatric Blood Cancer 57:183-184

46. Costa FF, Bischof JM, Rishi R, Lula RR, Wang M, Sredni SS, Rajaram V, Bonaldo MF, Vanin EF, Wang D, Goldman S, Tomita T, Soares MB (2011) Identification of microRNAs as potential prognostic markers in ependymoma. Public Libr Sci One 6(10):e25114

47. Sredni ST, Bonaldo M, Costa FF, Huang C-C, Hamm C, Rajaran V, Tomita T, Goldman S, Bischof J, Soares MB (2010) Upregulation of Mir 221 and Mir 222 in atypical/teratoid tumors/potential therapeutic target. Childs Nerv Syst 26:279-283

48. Sredoni S, Huang CC, de Bonaldo MF, Tomita T (2011) MicroRNA expression profiling for molecular classification of pediatric brain tumors. Pediatr Blood Cancer 57(1):183-184

49. Tomita T, McLone DG, Naidich TP (1984) Brain stem gliomas in childhood. Rational approach and treatment. J Neuro-Oncology 2:117122

50. Tomita T, Radkowski MA, Chaddia A (1990) Brain stem tumors in childhood; Correlation of CT findings with patients' outcome. Concepts Pediatric Neurosurg 10:78-96

51. Tomita T (1986) Surgical management of cerebellar peduncle lesions in childhood. Neurosurgery 18:568-575
52. Tomita T, Chou P, Reyes Mugica M (1998) Fourth ventricle astrocytomas: clinicopathological analysis of 21 cases. Childs Nerv Syst 14:537-546

53. Tomita T, Cortes RF (2002) Astrocytomas of the cerebral peduncle in children: surgical experience of seven patients. Childs Nerv Syst 18:225-230

54. Packer RJ, Allen JC, Goldwein JL, Newall J, Zimmerman RA, Priest J, Tomita T, Mandelbaum DE, Cohen BH, Finlay JL, Sutton LN, D’Angio G (1990) Hyperfractionated radiotherapy for children with brainstem gliomas: a pilot study using 7,200 cGy. Ann Neurol 27:167-173

55. Tange Y, Daneriallis DM, Kondo A, Mania-Farnell B, Nakazaki H, Rajaram V, Goldman S, Egorin MJ, Soares MB, Tomita T (2009) Interstitial continuous infusion therapy in a malignant glioma model in rats. Childs Nerv Syst 25:655-662

56. Kondo A, Goldman S, Vanin EF, Sredni ST, Rajaram V, Soares MB, Tomita T (2009) An experimental brainstem tumor model using in vitro bioluminescence imaging in rat. Childs Nerv Syst 25:527-533

57. Xi G, Mania-Farnell B, Veena Rajaram V, Mayanil C, Soares MS, Tomita T, Goldman S (2012) Efficacy of interstitial continuous vincristine infusion in a bioluminescent rodent intracranial tumor model. J Neurooncology 106(2):261-270

58. Xi G, Tomita T, Rajaram V, Mania-Farnell B, Ichi S, Mayanil SC, Soares MB, Goldman S (2012) Efficacy of vincristine administered via convection-enhanced delivery in a rodent brainstem tumor model documented by bioluminescence imaging. Childs Nerv Syst 28(4):565-574

59. Ris MD, Walsh K, Wallace D, Armstrong FD, Holmes E, Gajjar A, Zhou T, Packer RJ (2013) Intellectual and academic outcome following two chemotherapy regimens and radiotherapy for average-risk medulloblastoma: COG A9961. Pediatr Blood Cancer. doi: $10.1002 / \mathrm{pbc} .24496$

60. Tomita T, Bowman RM (2005) Craniopharyngiomas in children: surgical experience at Children's Memorial Hospital. Child's Nerv Syst 21:729-746 